\title{
Monotonic Loading Tests of RC Beam-Column Subassemblage Strengthened to Prevent Progressive Collapse
}

\author{
Jinkoo Kim ${ }^{1), *}$, and Hyunhoon $\mathrm{Choi}^{2)}$
}

(Received August 12, 2015, Accepted November 7, 2015, Published online November 20, 2015)

\begin{abstract}
In this study the progressive collapse resisting capacity of a RC beam-column subassemblage with and without strengthening was investigated. Total of five specimens were tested; two unreinforced specimens, the one designed as gravity loadresisting system and the other as seismic load-resisting system, and three specimens reinforced with: (i) bonded strand, (ii) unbonded strand, and (iii) side steel plates with stud bolts. The two-span subassemblages were designed as part of an eight-story RC building. Monotonically increasing load was applied at the middle column of the specimens and the force-displacement relationships were plotted. It was observed that the gravity load-resisting specimen failed by fractures of re-bars in the beams. In the other specimens no failure was observed until the maximum displacement capacity of the actuator was reached. Highest strength was observed in the structure with unbonded strand. The test result of the specimen with side steel plates in beam-column joints showed that the force-displacement curve increased without fracture of re-bars. Based on the test results it was concluded that the progressive collapse resisting capacity of a $\mathrm{RC}$ frame could be significantly enhanced using unbonded strands or side plates with stud bolts.
\end{abstract}

Keywords: progressive collapse, beam-column sub-assemblage, catenary action, side plates.

\section{Introduction}

After collapse of the World Trade Center twin towers in New York, protection of structures against progressive collapse has been an important issue in the field of structural engineering. Researches have been conducted on the collapse behavior of moment-resisting frames caused by sudden loss of columns (Khandelwal and El-Tawil 2005; Tsai and Lin 2008; Kim and An 2009). Milner et al. (2007) and Sasani and Kropelnicki (2008) carried out experiments to investigated the behavior of a scaled model of a continuous perimeter beam in a reinforced concrete frame structure following the removal of a supporting column. Yi et al. (2008) carried out static experimental study of a three-story $\mathrm{RC}$ frame structure to investigate progressive failure due to the loss of a lower story column. In those experiments it was observed that after the plastic mechanism formed, the concrete strain in the compression zone at the beam ends reached its ultimate compressive strain, and the compressive re-bars were gradually subject to tension with increasing displacement. Choi and Kim (2011) investigated the

\footnotetext{
${ }^{1)}$ Department of Civil and Architectural Engineering, Sungkyunkwan University, Suwon, Korea. *Corresponding Author; E-mail: jkim12@skku.edu

${ }^{2)}$ Research Institute of Technology, Samsung

Engineering and Construction Co., Ltd., Seoul, Korea.

Copyright $($ The Author(s) 2015. This article is published with open access at Springerlink.com
}

progressive collapse resisting capacity of RC beam-column subassemblages designed with and without seismic load. Qian and Li (2012) carried out experimental study of six RC beam-column substructures with different design detail, span length and span aspect ratio to investigate the dynamic load redistribution performance. Yu and Tan (2013) carried out an experimental program for investigating progressive collapse resistance of reinforced concrete (RC) beam-column subassemblages under a middle column removal scenario. Two one-half scaled sub-assemblages were designed with seismic and non-seismic detailing to check the effect of detailing on structural behavior. Song and Sezen (2013) performed a field experiment and numerical simulations to investigate the progressive collapse potential of an existing steel frame building. Four first-story columns were physically removed from the building to understand the subsequent load redistribution within the building. In Qian and Li (2013) experimental study of seven one-third scale RC beam-column substructures were tested to investigate the effect of beam transverse reinforcement ratios, type of design detailing, and beam span aspect ratios. Recently Qian et al. (2015) tested 6 one-quarter scaled specimens to investigate the progressive collapse resisting capacity of RC frames including secondary mechanisms such as membrane actions developed in slabs. Kang et al. (2015) carried out experimental investigation on the behavior of precast concrete beam-column sub-assemblages with engineered cementitious composites (ECC) in structural topping and beam-column joints under middle column removal scenarios to investigate the effectiveness of ECC on mitigating progressive collapse. 
In this study monotonic loading tests of five $\mathrm{RC}$ beamcolumn subassemblages, two unstrengthened and three strengthened specimens, were carried out to investigate their progressive collapse resisting capacity and to observe the effect of the reinforcement methods. The two-span subassemblage specimens were designed as part of an eightstory RC moment resisting framed building. Three specimens were reinforced with: (i) bonded strands, (ii) unbonded strands, and (iii) side steel plates, and their relative effectiveness in enhancing progressive collapse resisting capacity was addressed. Two unreinforced specimens, the one designed as gravity load-resisting system and the other as seismic load-resisting system, were also tested for comparison.

\section{Design of Prototype Structures}

As prototype structures of the test specimens two eightstory reinforced concrete structures were designed. The story height of the model structure is $3.5 \mathrm{~m}$, and the design dead and live loads are 5.9 and $2.45 \mathrm{kN} / \mathrm{m}^{2}$, respectively. The design spectral response acceleration parameters for seismic load, $S_{D S}$ and $S_{D 1}$, are 0.44 and 0.23 , respectively in the IBC 2009 (ICC 2009) format. The design compressive strength of concrete $\left(f_{c}^{\prime}\right)$ is $27 \mathrm{MPa}$ and the yield strength of re-bars $\left(f_{y}\right)$ is $392 \mathrm{MPa}$. Figure 1a shows the structural plan of the prototype structure with core shear walls. In this model all the lateral force is resisted by the shear walls and the ordinary moment frames were designed to resist only gravity loads. Figure 1b shows the structural plan of the other model structure composed of intermediate moment-resisting frames which were designed to resist both gravity and lateral loads.

\section{Design of Specimens and Test Setup}

To evaluate the progressive collapse resisting capacity of the model structures when subjected to sudden removal of a column, a part of the exterior frame enclosed in the dotted curve in Fig. 1 were manufactured for tests. Total of five specimens, scaled to $37 \%$ of the prototype structure, were constructed for the loading tests: two unstrengthened and three strengthened specimens. The subassembly test specimens are composed of three columns (C2) and two beams (G1) located between the columns. Figure 2 shows the rebar placements of the specimens for the gravity load-resisting system and the seismic load-resisting system. To take into account the continuation effect of beams in the prototype structure, the two columns at both sides of a specimen were made to be 1.5 times larger than the center column in size. The longitudinal bars were anchored to the columns with the tail extension of the hook. The re-bar detailing was based on the ACI Detailing Manual (2004). In the case of non-seismically designed specimens, bottom re-bars were extended into the support (the exterior column) without hook, whereas the top and bottom bars of the seismically designed specimen were anchored with standard 90 degree

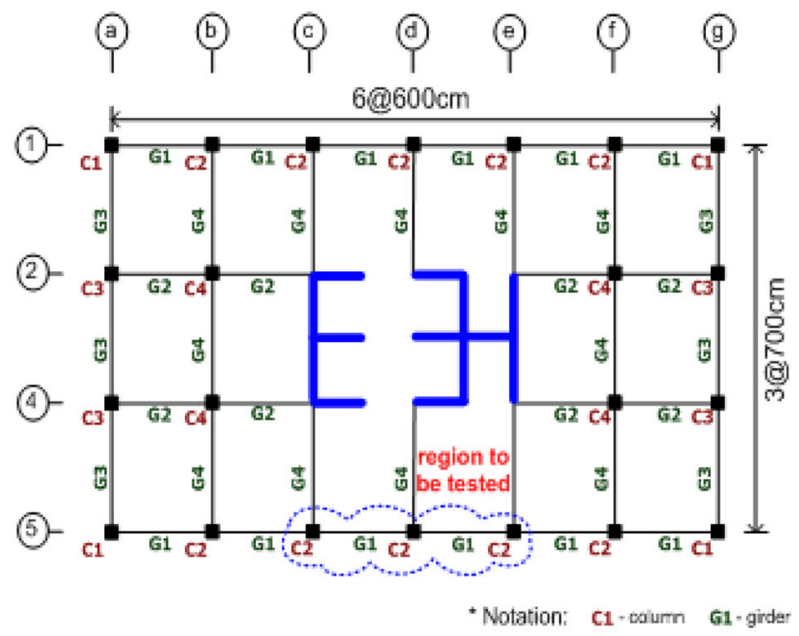

(a)

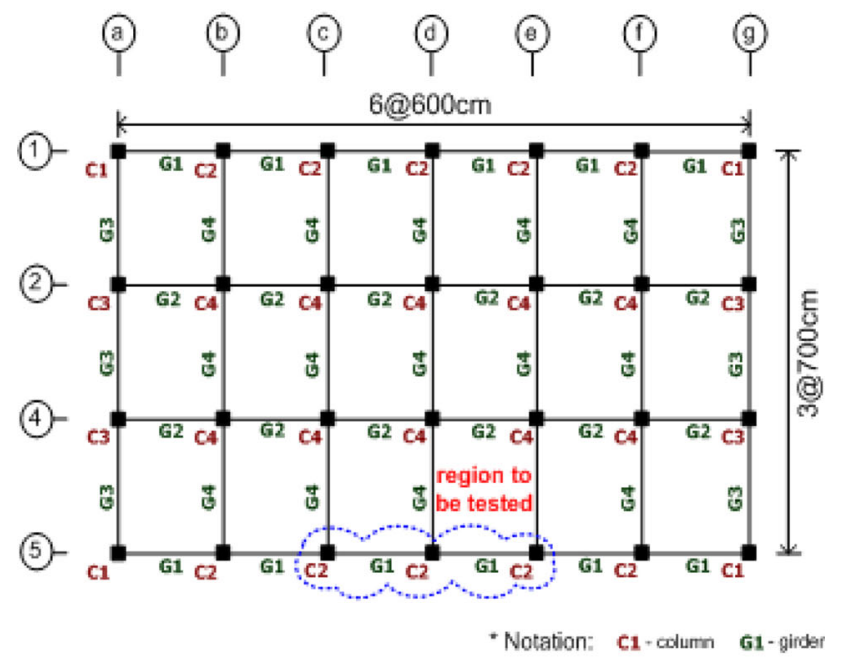

(b)

Fig. 1 Structural plans of prototype structures. a RC moment resisting frames with shear walls. b RC moment resisting frames.

hook into exterior columns. The D10 re-bars with nominal diameter of $9.53 \mathrm{~mm}$ were used for main reinforcing steel for beams and columns, and $\varphi 6$ steel bars were used for stirrups and tie bars in the specimens. From coupon tests it was observed that the yield strengths of the main re-bars and stirrups/tie bars are 457 and $325 \mathrm{MPa}$, respectively. The size of the specimens and the number of re-bars are summarized in Table 1.

To increase the progressive collapse resisting capacity, the specimen out of the gravity load-resisting system was strengthened by either high strength strand or steel side plates welded with stud bolts. Figure 3 shows the test specimen for gravity load-resisting system strengthened with a wire strand with diameter of $12.7 \mathrm{~mm}$. The strand was placed along the center of the cross-section of the beams before casting of concrete without prestress, and was anchored at the exterior surfaces of the two end columns using an anchorage as shown in Fig. 4. To compare the effects of bonded and unbonded strands, one specimen was prepared with a bonded strand and another specimen was prepared with an unbonded strand located within a sheath 


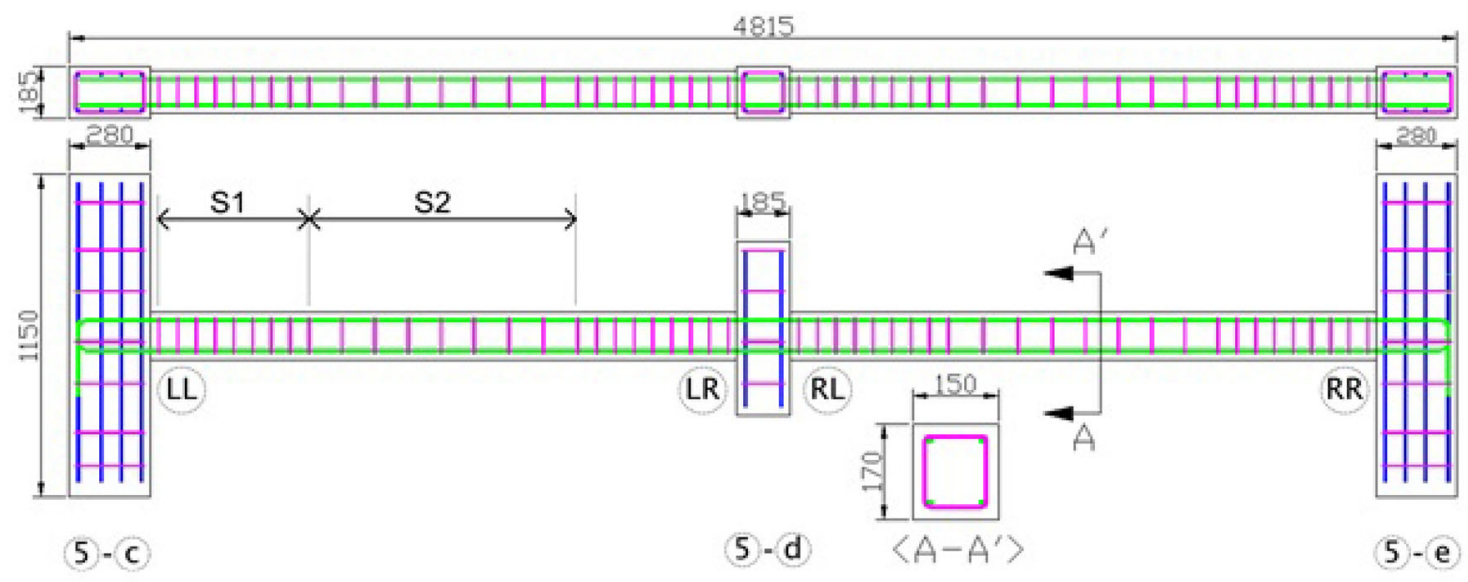

(a)

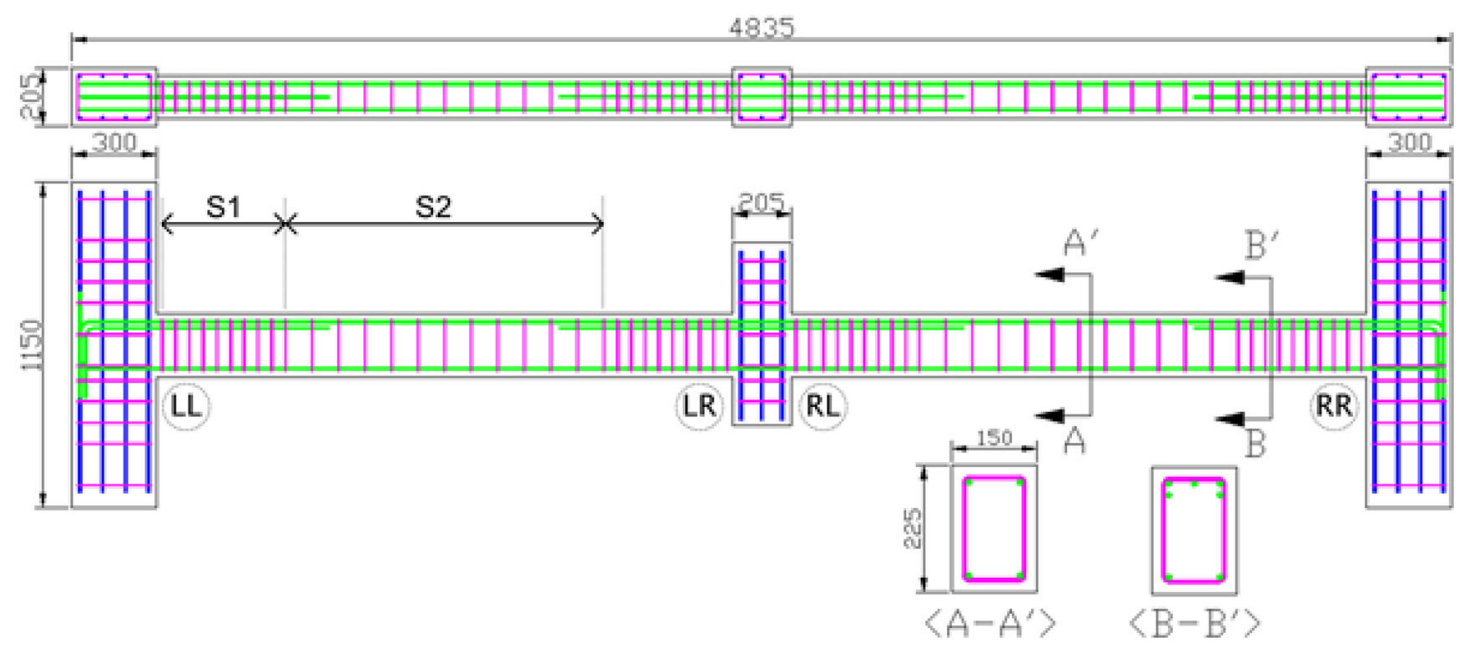

(b)

Fig. 2 Re-bar placement in the test specimens. a Gravity-load resisting system. b Lateral-load resisting system.

pipe. For existing structures the high strength tendons can be installed at both sides of the beams similarly to the external prestressing used to retrofit old structures. External prestressing techniques for strengthening beams can be found elsewhere (Harajli 1993; Shin et al. 2013). The other strengthening scheme is to attach steel side plates at both sides of beam ends as shown in Fig. 5. To increase the flexural strength of a beam for gravity load, steel plates are generally attached in the middle of the beam where bending moment is maximized (Ren et al. 2015). In this study, for resisting progressive collapse caused by loss of a column, they were placed at the ends of the beams in the form of side plates. Thirteen high strength bolts with diameter of $8 \mathrm{~mm}$ were welded in two rows to the $5 \mathrm{~mm}$-thick side plates as shear connectors to ensure composite action of the plates and the specimen as depicted in Fig. 6. The side plates were installed in position before concrete was poured. However they also can easily be attached to sides of existing beams using chemical anchor bolts.

Figure 7 shows the test setup for the specimens. The rightand left-side-columns were fixed to the jigs and the actuator was connected to the middle column. It was assumed that the column at the location of (5)-(d) of the prototype structure shown in Fig. 1a was suddenly removed by accident, and displacement-controlled monotonic pushdown force was enforced at the middle column of the specimens using a hydraulic actuator with maximum capacity of $2000 \mathrm{kN}$ and maximum stroke of $\pm 250 \mathrm{~mm}$. The tests were carried out horizontally and to prevent vertical deflection of the specimens due to self weight, rollers were placed beneath the beam-column joint during the. Strain gages were attached on the longitudinal re-bars and strands located at the ends of girders.

\section{Test Results}

\subsection{Unstrengthened Specimens}

Displacement controlled monotonic loading tests were conducted on the five specimens by gradually increasing the displacement at the center column until the displacement capacity of the hydraulic actuator was reached. The forcedisplacement relationship of the gravity load-resisting specimen not strengthened by strands or side plates is 
Table 1 Dimensions and rebar placements of test specimens (unit: $\mathrm{mm}$ ).

\begin{tabular}{|c|c|c|c|c|c|}
\hline \multicolumn{2}{|c|}{ Members } & Column (C2) & \multicolumn{3}{|c|}{ Girder (G1) (depth $\times$ width) } \\
\hline \multicolumn{6}{|c|}{ (a) Gravity load resisting system } \\
\hline \multirow[t]{4}{*}{ Prototype structure } & Size & $500 \times 500$ & \multicolumn{3}{|c|}{$450 \times 400$} \\
\hline & \multirow[t]{3}{*}{ Rebar } & \multirow[t]{3}{*}{$4 \mathrm{D} 25$} & Location & End & Center \\
\hline & & & Upper & 2D25 & $2 \mathrm{D} 25$ \\
\hline & & & Lower & $2 \mathrm{D} 25$ & $2 \mathrm{D} 25$ \\
\hline \multirow[t]{6}{*}{ Test specimen } & Size & $185 \times 185$ & \multicolumn{3}{|c|}{$170 \times 150$} \\
\hline & \multirow[t]{5}{*}{ Rebar } & \multirow[t]{5}{*}{ 4D10 } & Location & End & Center \\
\hline & & & Upper & 2D10 & 2D10 \\
\hline & & & Lower & 2D10 & 2D10 \\
\hline & & & \multirow[t]{2}{*}{ Stirrup } & S1 & ф6@65 \\
\hline & & & & S2 & ф6@117 \\
\hline
\end{tabular}

(b) Lateral load resisting system

\begin{tabular}{|c|c|c|c|c|c|}
\hline \multirow[t]{5}{*}{ Prototype structure } & Size & $550 \times 550$ & & $00 \times 40$ & \\
\hline & \multirow[t]{4}{*}{ Rebar } & \multirow[t]{4}{*}{$6 \mathrm{D} 25$} & Location & End & Center \\
\hline & & & \multirow[t]{2}{*}{ Upper } & $3 \mathrm{D} 25$ & \multirow[t]{2}{*}{$2 \mathrm{D} 25$} \\
\hline & & & & $2 \mathrm{D} 25$ & \\
\hline & & & Lower & $2 \mathrm{D} 25$ & 2D25 \\
\hline \multirow[t]{7}{*}{ Test specimen } & Size & $205 \times 205$ & \multicolumn{3}{|c|}{$225 \times 150$} \\
\hline & \multirow[t]{6}{*}{ Rebar } & \multirow[t]{6}{*}{$6 \mathrm{D} 10$} & Location & End & Center \\
\hline & & & Upper & $3 \mathrm{D} 10$ & \multirow[t]{2}{*}{ 2D10 } \\
\hline & & & & $2 \mathrm{D} 10$ & \\
\hline & & & Lower & $2 \mathrm{D} 10$ & $2 \mathrm{D} 10$ \\
\hline & & & \multirow[t]{2}{*}{ Stirrup } & S1 & b6@48 \\
\hline & & & & S2 & $\phi 6 @ 93$ \\
\hline
\end{tabular}

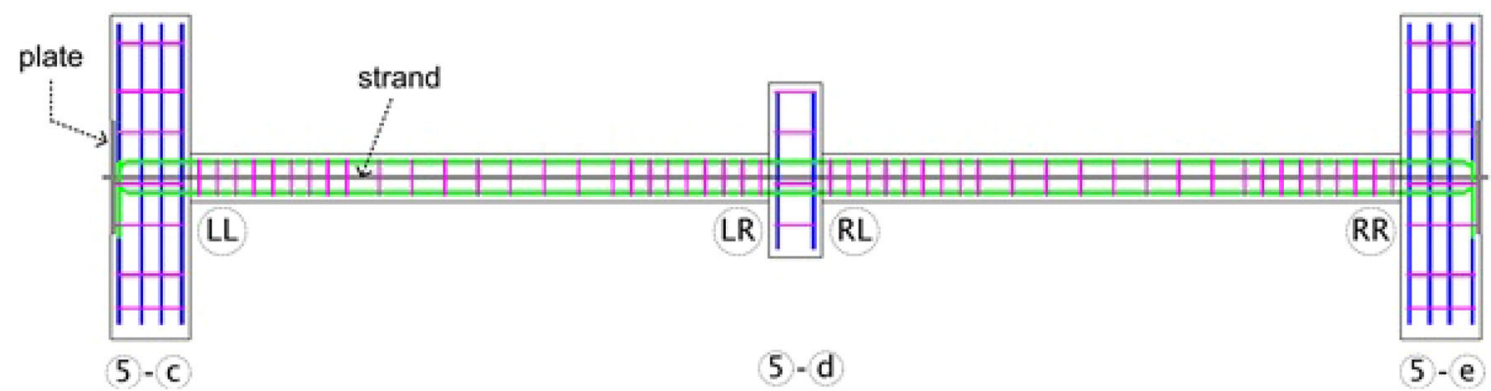

Fig. 3 Specimen strengthened with high-strength strands.

presented in Fig. 8. The arrow mark $\measuredangle$ represents the fracture of re-bars. The specimen started to yield at the displacement around $40 \mathrm{~mm}$, and full plastic hinge formed at the displacement of about $90 \mathrm{~mm}$. When the displacement reached about $180 \mathrm{~mm}$ the strength increased again due to the activation of catenary force of the re-bars. The curve for the specimen dropped slightly at displacement of $293 \mathrm{~mm}$ when one of the tension re-bars fractured. The strength further increased and more re-bar fractured as more displacement was imposed on the specimen, and at displacement of $426 \mathrm{~mm}$ one of the interior ends of the beam was completely separated from the column and the specimen failed. The failure criterion for beams recommended in the GSA guidelines is 0.015 radian, which corresponds to vertical displacement of $214 \mathrm{~mm}$ in the specimen with clear span of $2035 \mathrm{~mm}$. Therefore the displacement at failure of 


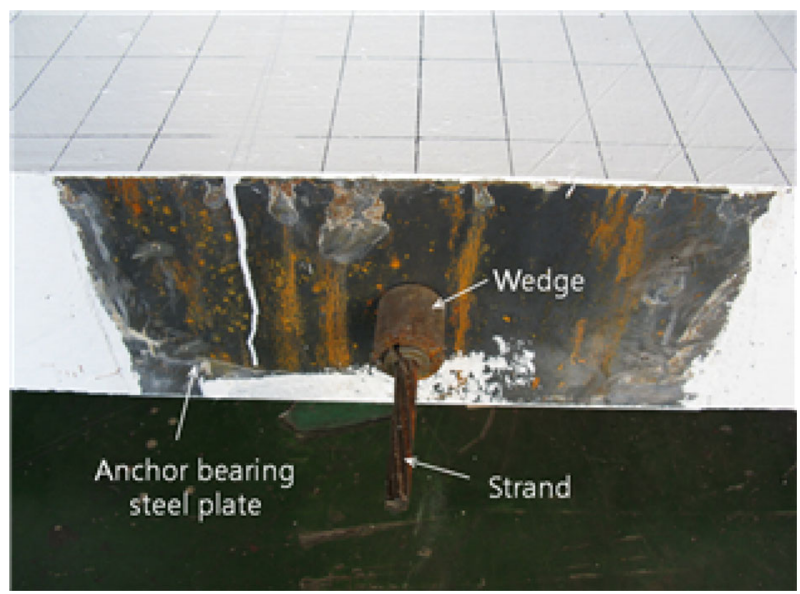

Fig. 4 Details of anchorage for strand. the specimen far exceeded the limit state specified in the guidelines. It also can be noticed that the GSA-specified failure point corresponds to the displacement where the catenary force started to be activated. Figure 9 shows the photograph of the specimen at failure. Major cracks were observed only at both ends of the beams, and relatively few cracks formed in the external columns.

The force-displacement relationship of the lateral loadresisting specimen is presented in Fig. 10. The specimen started to yield at the displacement around $100 \mathrm{~mm}$, which is significantly larger than the first yield point of the gravity load-resisting system. The yield strength of the specimen is also more than twice as high as that of the gravity loadresisting system. After the strength reached $41 \mathrm{kN}$ at the displacement of $144 \mathrm{~mm}$, the flexural strength of the specimen started to decrease as a result of yield of re-bars and

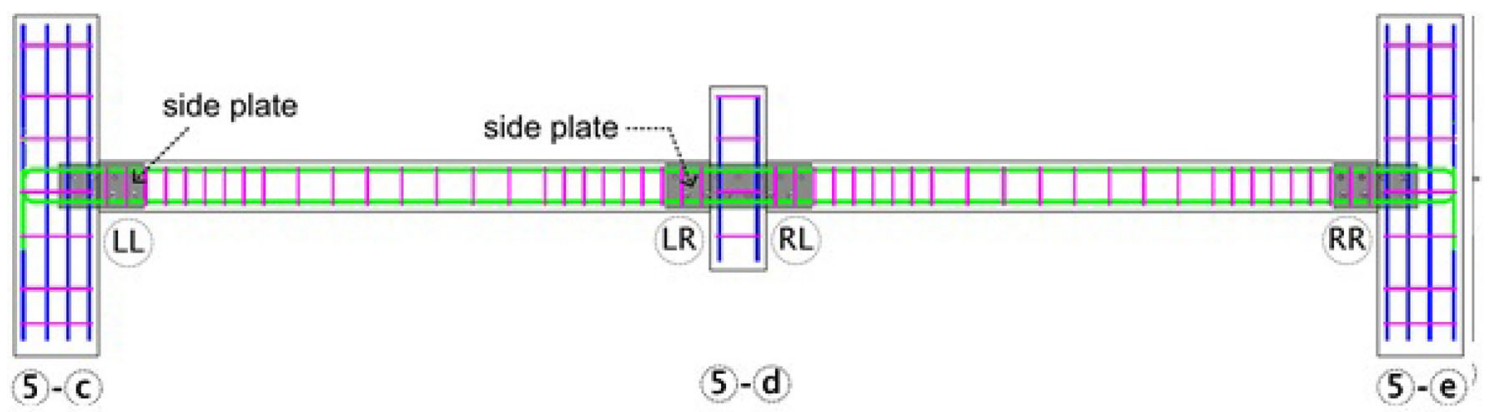

Fig. 5 Specimen strengthened with steel side plates.

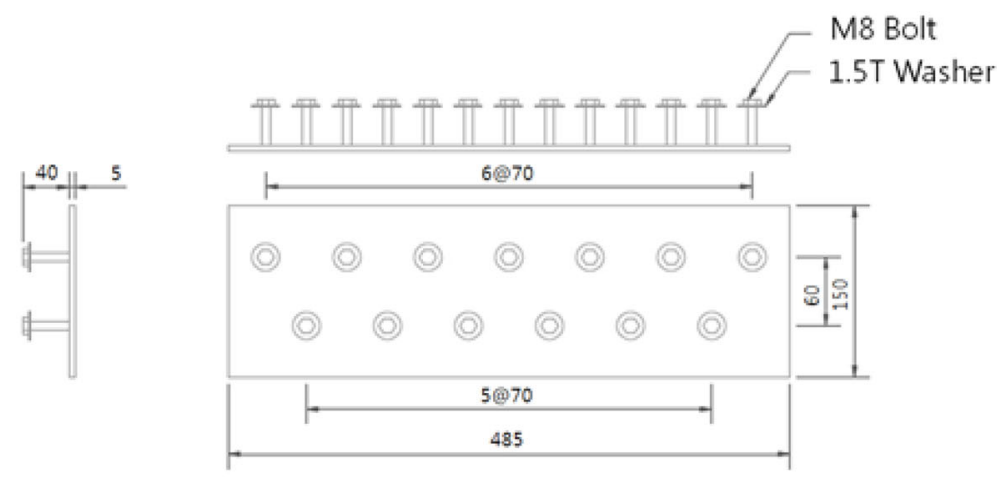

(a)

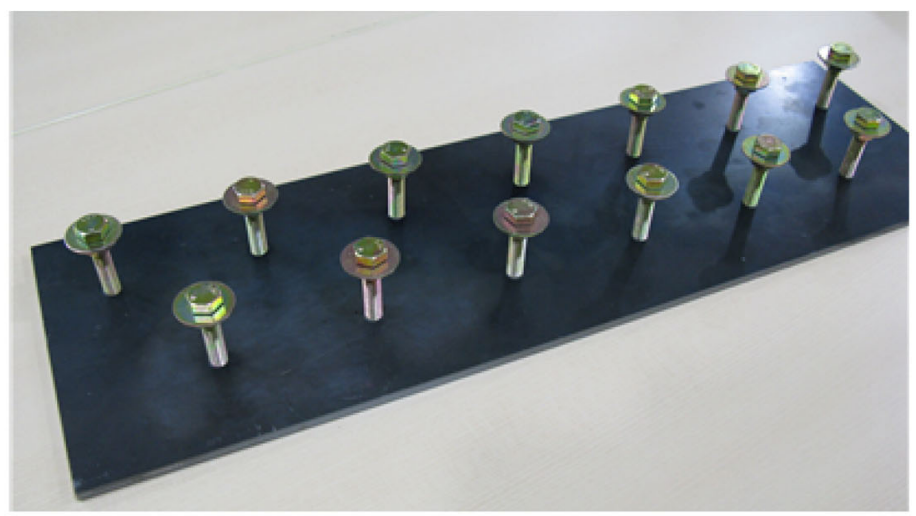

(b)

Fig. 6 Configuration and detailing of a steel side plate. a Dimensions of a side plate. $\mathbf{b}$ Side plate with stud bolts. 


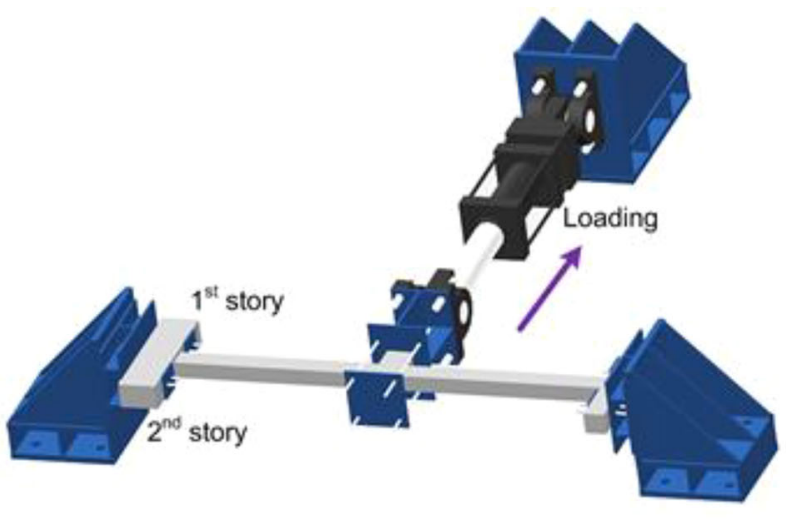

(a)

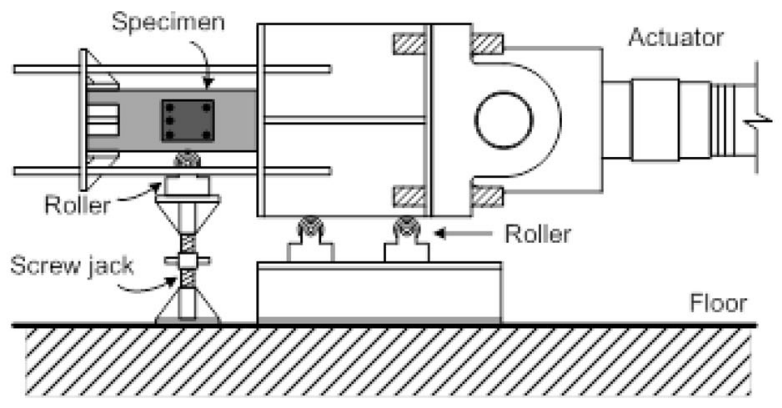

(b)

Fig. 7 Test setup for a subassemblage specimen. a Overall view. b Roller support at the beam-column joint.

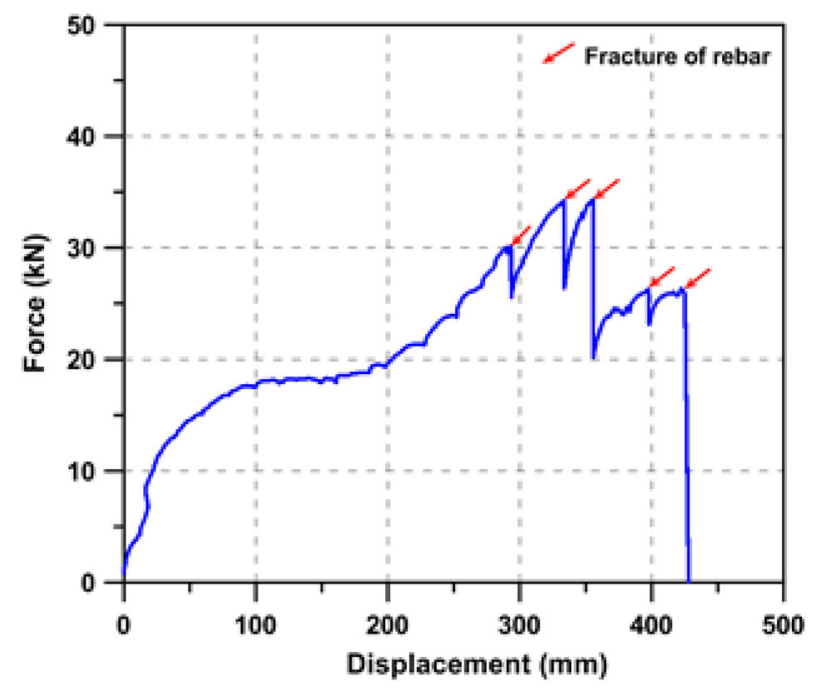

Fig. 8 Load-displacement relationship of the specimen for a gravity-load resisting system.

formation of microcracks. The strength dropped to $54 \%$ of the peak value due to fracture of tension re-bars at the displacements of 198 and $209 \mathrm{~mm}$. The strength increased again up to $27 \mathrm{kN}$ before another re-bar fractured and the strength suddenly dropped. The strength increased again to $44 \mathrm{kN}$ and dropped again at the displacement of about $400 \mathrm{~mm}$ due to fracture of another re-bars. Then the strength re-increased due to catenary force of remaining re-bars. The maximum displacement capacity of the actuator was reached

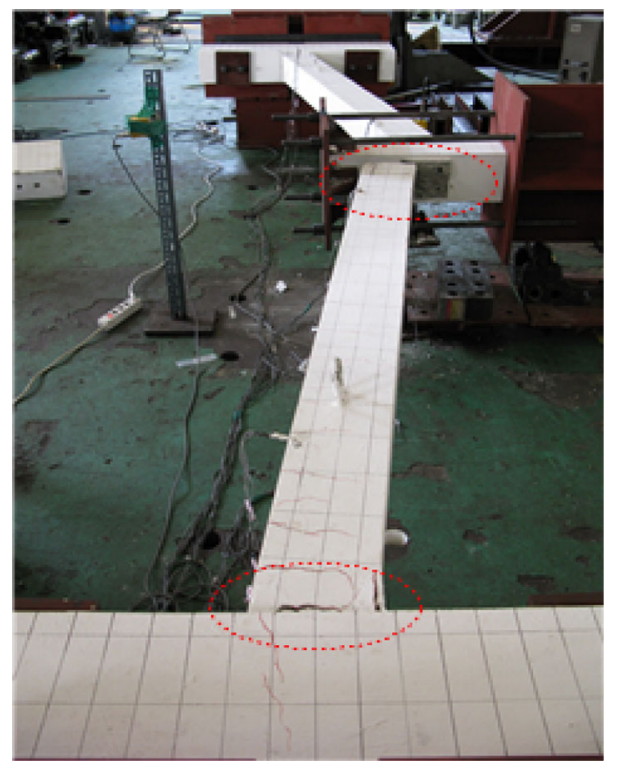

Fig. 9 Failure mode of the gravity-load resisting specimen.

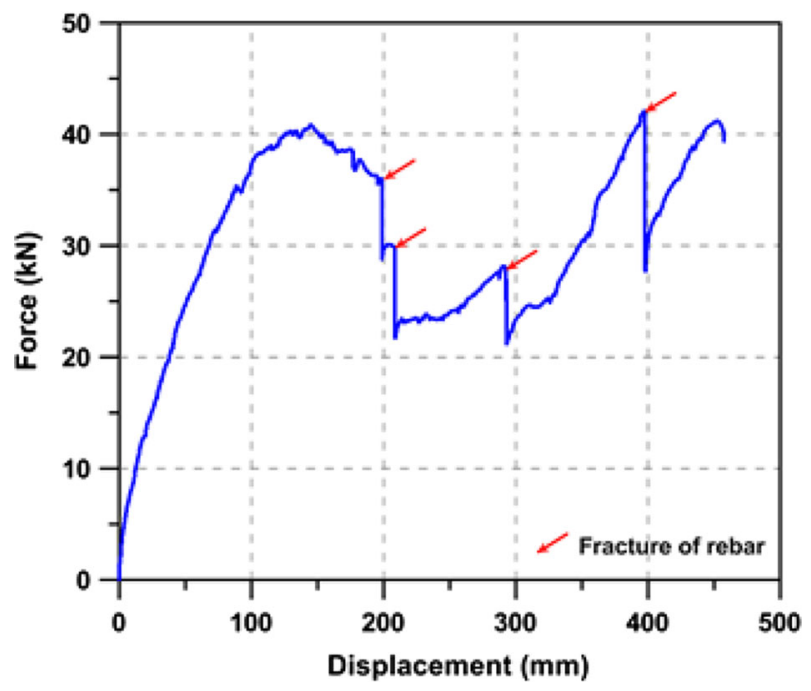

Fig. 10 Load-displacement relationship of the specimen for a lateral-load resisting system.

and the test stopped right after the strength re-increased to another peak point. Figure 11 shows the overall view of the damaged specimen after the test was over. It was observed that the plastic hinges formed away from the column faces where the closer stirrup spacing was no longer required. Due to the enhanced shear reinforcement at the ends of the beams and the seismic detailing of re-bars at the beam-column joints including anchoring of bottom re-bars using standard hooks, the effective length of the beam was reduced and consequently the maximum bending strength was increased. The number of fractured re-bars was also reduced compared with the case of gravity load-resisting system. The number of cracks formed in the exterior column was slightly larger than that of the specimen designed only for gravity load. Figure 12 shows the damaged region of the specimen, where it was noticed that the cross-sectional areas of the fractured re-bars were slightly reduced representing typical tension failure. 


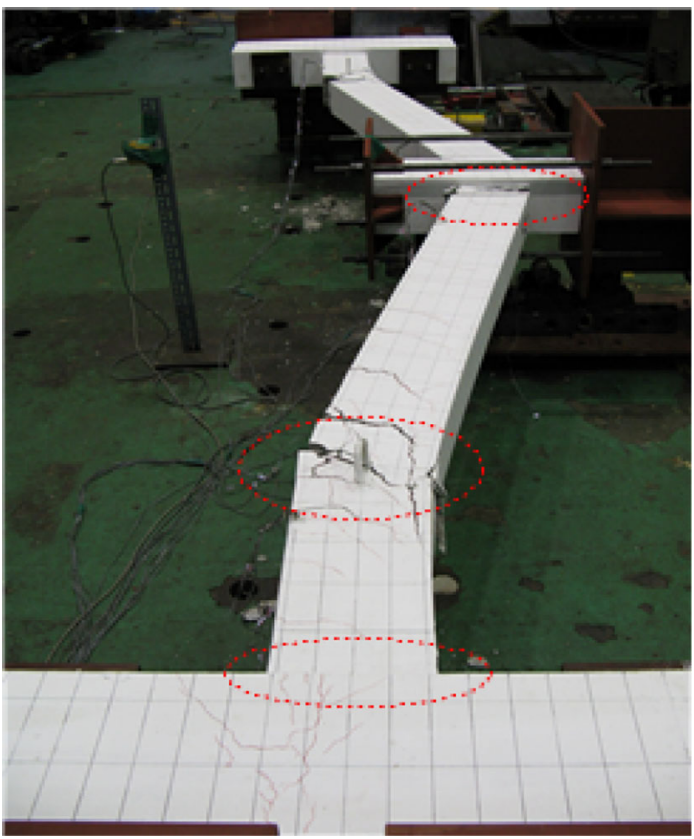

Fig. 11 Failure mode of the lateral-load resisting specimen.
The variation of rebar strain in the gravity-load resisting specimen is shown in Fig. 13. It can be observed in Fig. 13a that the strain of the top rebars of the left end of the righthand-side beam (location RL in Fig. 2a), which was initially subjected to compression, started to resist tension after the displacement exceeded $40 \mathrm{~mm}$. The tension increased rapidly at the displacement of $330 \mathrm{~mm}$ due to the initiation of catenary action. Similar phenomenon was observed in the re-bars located in the right end of the beam (location RR in Fig. 2a) as shown in Fig. 13b. It can be observed that the strain of the bottom bar rapidly increased starting from the displacement of $330 \mathrm{~mm}$ due to catenary action. Figure 14 shows the rebar strain in the lateral-load resisting specimen, where it can be noticed that the activation of catenary action is apparent compared with the case of the gravity load resisting specimen. It can be observed that the bottom rebar in the right-end of the right-hand-side beam (location RR in Fig. 2b), which was initially under compression, started to be subjected to tension at the vertical displacement of $400 \mathrm{~mm}$. Therefore if the test had not been terminated early due to the limitation of the displacement capacity of the

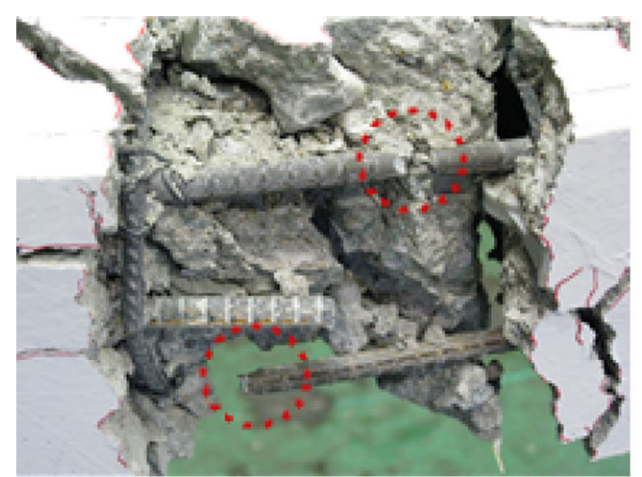

(a)

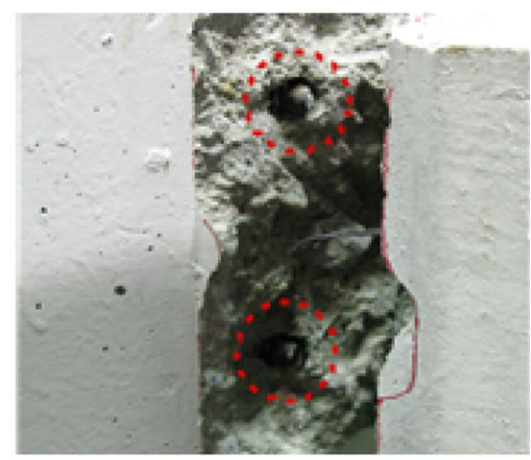

(b)

Fig. 12 Fracture of beam main rebars in the lateal-load resisting system. a Center. b End.

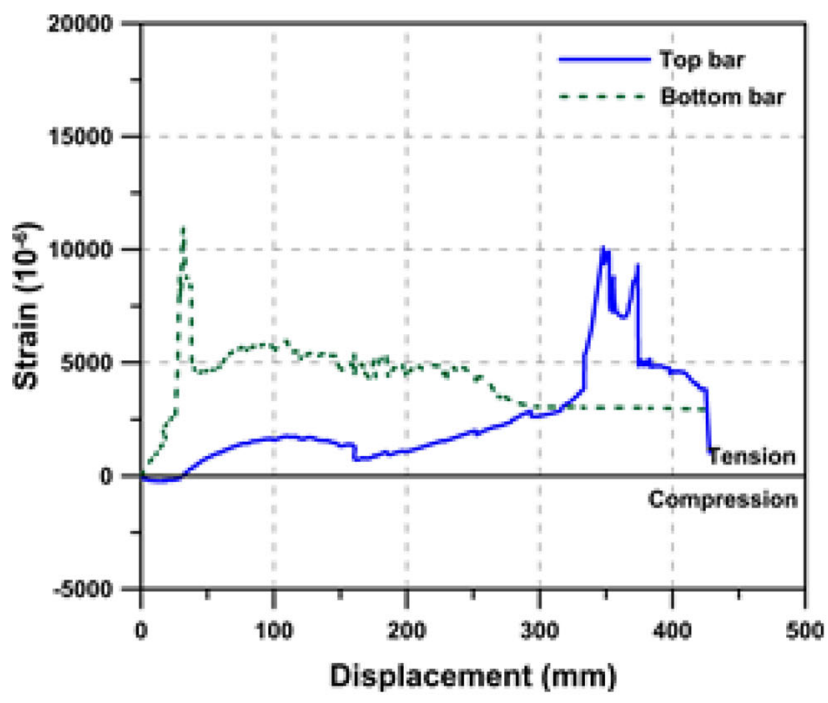

(a)

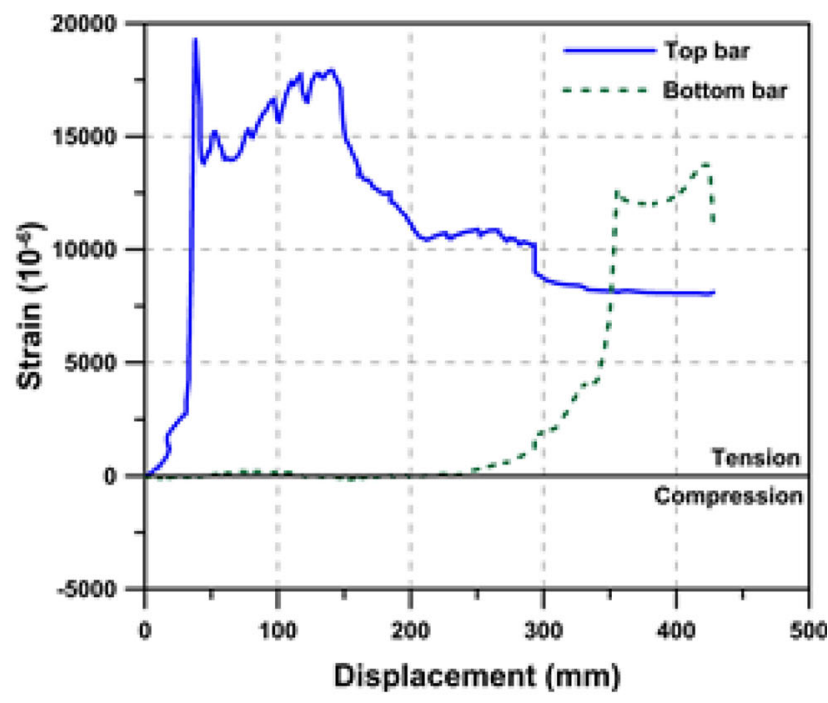

(b)

Fig. 13 Strain of rebars in the right-hand side beam of the gravity load resisting specimen. a Left end (RL). b Right end (RR). 


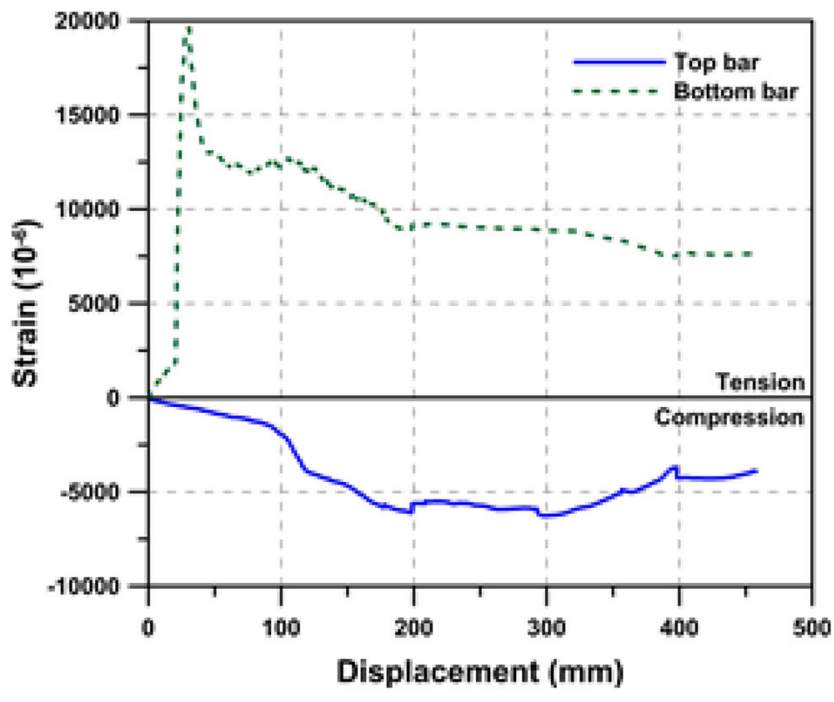

(a)

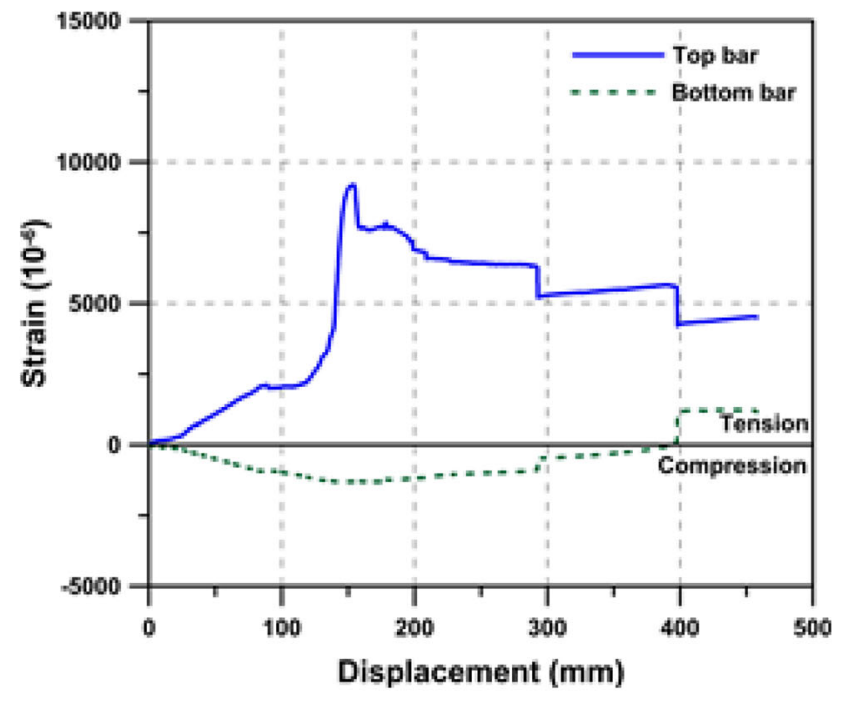

(b)

Fig. 14 Strain of rebars in the right-hand side beam of the lateral load resisting specimen. a Left end (RL). b Right end (RR).

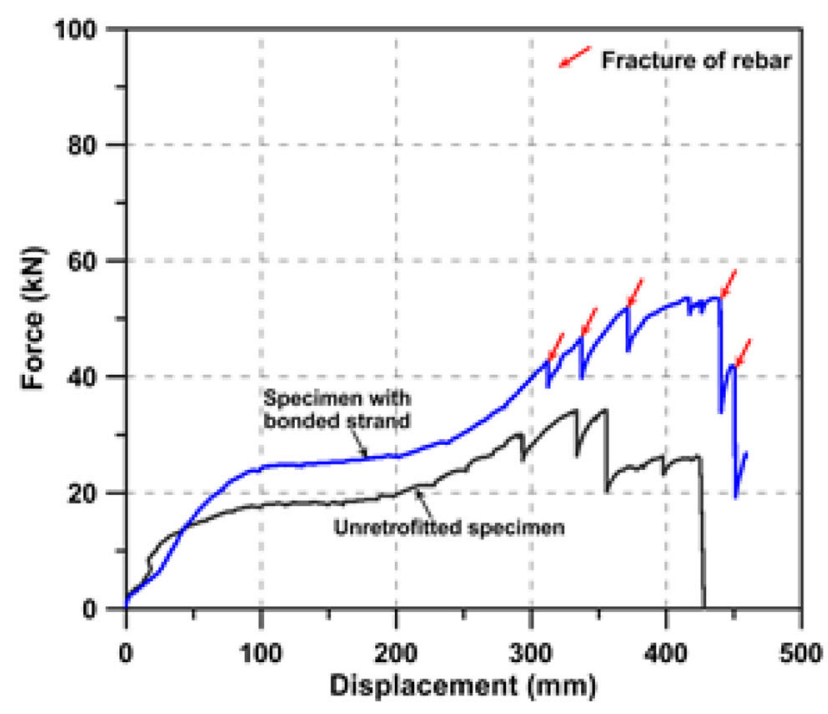

(a)

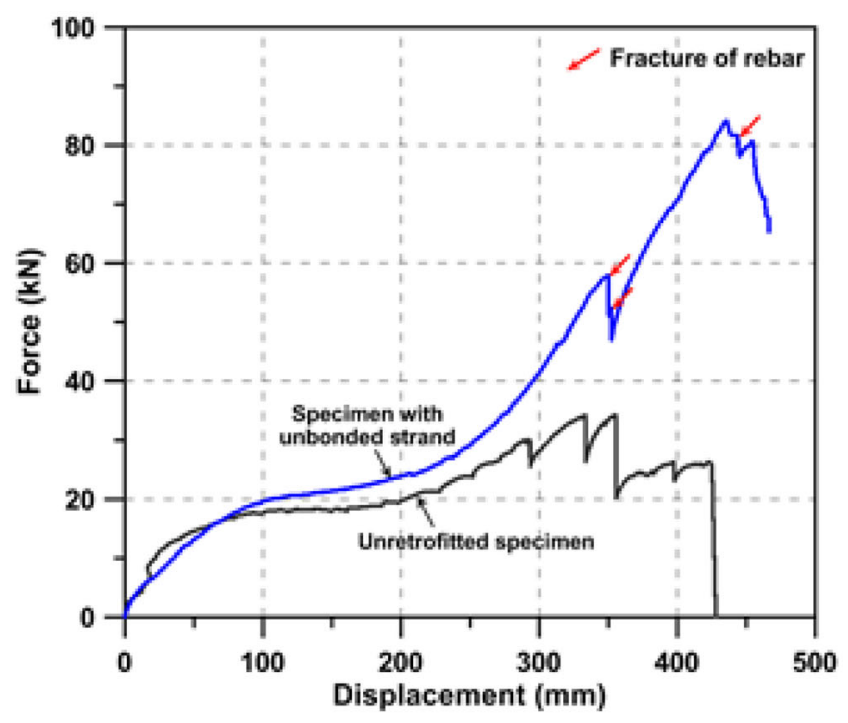

(b)

Fig. 15 Load-displacement relationship of the specimen reinforced with high-strength strand. a Bonded strand. b Unbonded strand.

actuator, more catenary force might have been observed in this specimen. The activation of catenary action in beams with different boundary conditions can be found in Kim and An (2009).

\subsection{Strengthened Specimens}

The specimen of gravity load system, which showed inferior performance to the specimen designed for seismic load, was reinforced by either high strength strand or side plates to enhance its progressive collapse resisting capacity. The forcedisplacement relationships of the specimens strengthened by bonded and unbonded strands are shown in Fig. 15. The force-displacement curve for the unstrengthened specimen was also plotted in each figure for comparison. The specimen reinforced with bonded strand showed similar force-displacement relationship to that of the unstrengthened specimen, except that the maximum strength increased by $56 \%$ and the specimen did not fail completely when the test was over. The number of re-bars fractured was seven, which is the same with that observed in the test of the unstrengthened specimen. In the specimen with unbonded strand, the maximum strength turned out to be $145 \%$ higher than the maximum strength of the specimen without the strand. It was also observed that two re-bars fractured at the displacement of $350 \mathrm{~mm}$, and the force was reduced for about $50 \mathrm{kN}$. As displacement further increased the force increased again until the strength reached the maximum value of $84 \mathrm{kN}$ at the displacement of $436 \mathrm{~mm}$. The number of fractured re-bars was reduced to three. It can be observed from the figures that the specimen with an unbonded strand showed superior catenary action to that of the specimen with bonded strand.

Figure 16 depicts the strain history of the high strength strand located at the right-end of the left-hand-side beam (LR) and in the right-end of the right-hand-side beam (RR). 


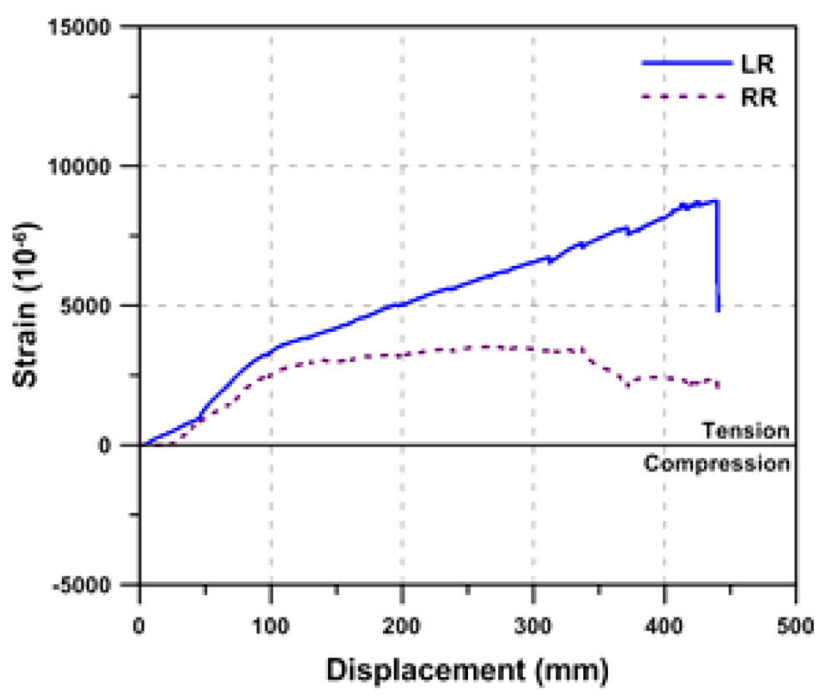

(a)

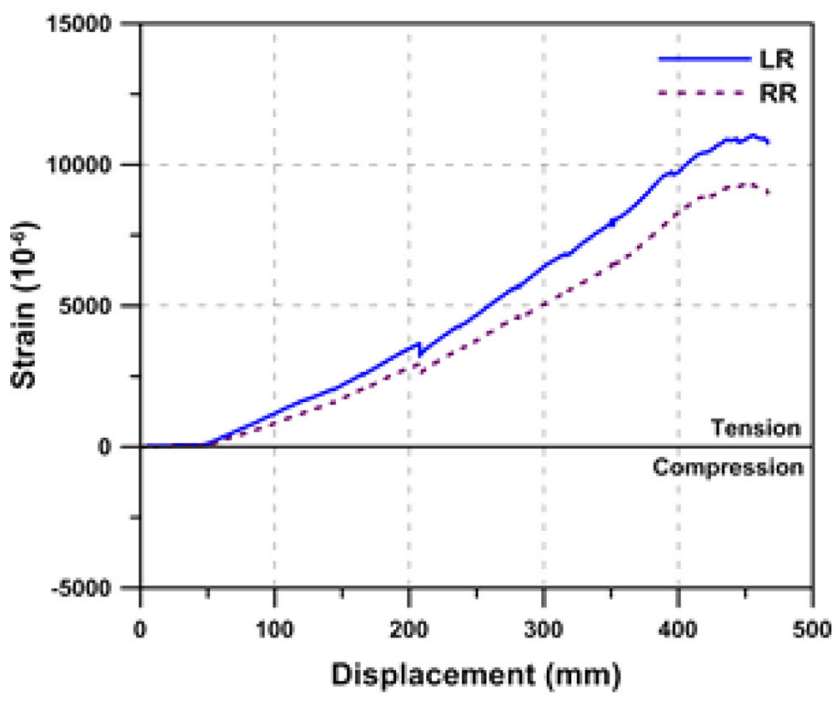

(b)

Fig. 16 Strain-displacement relationship of the strand. a Bonded strand. b Unbonded strand.

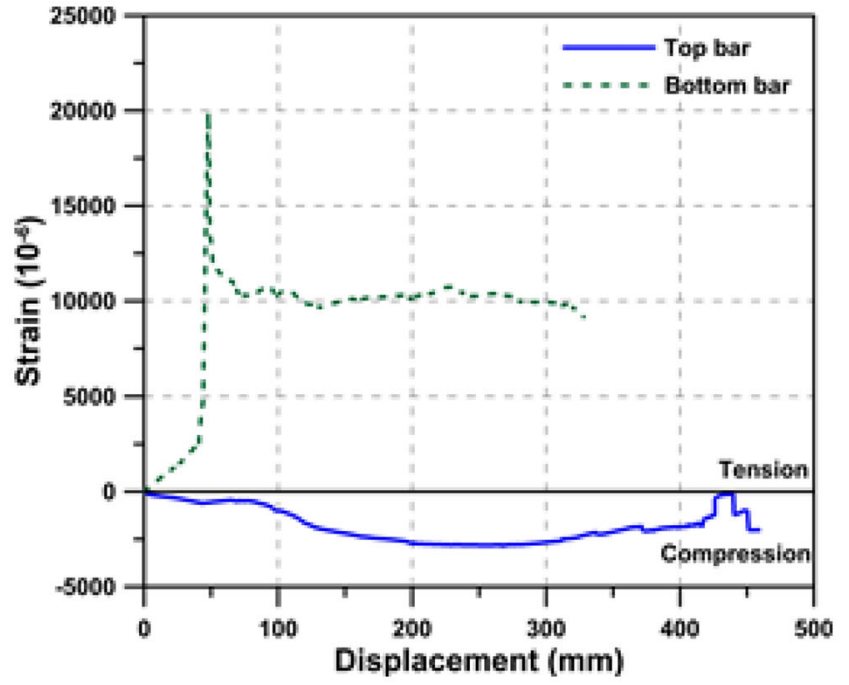

(a)

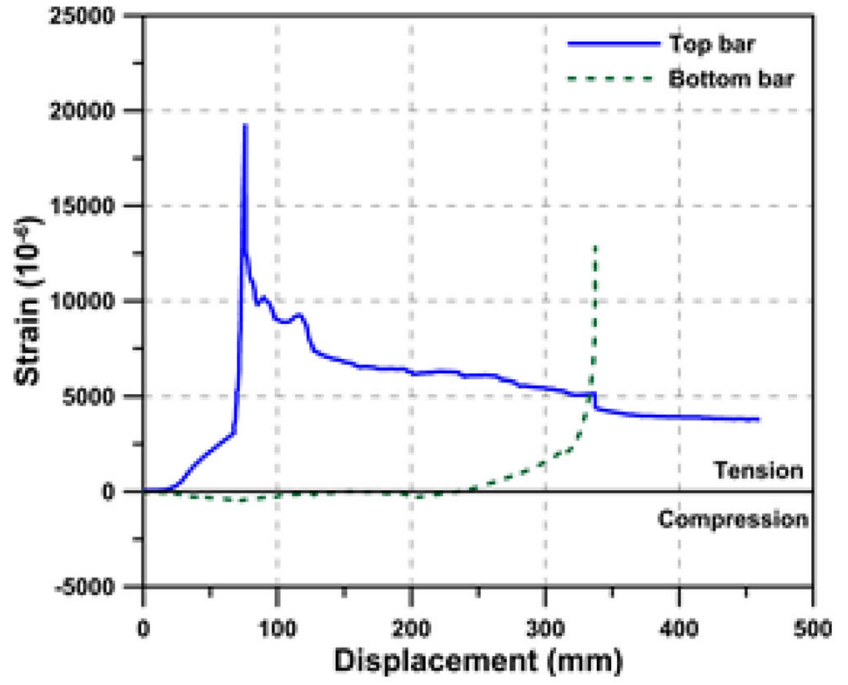

(b)

Fig. 17 Strain of rebars in the right-hand side beam of the gravity load resisting specimen strengthened by bonded strand. a Left end (RL). b Right end (RR).

It can be observed that, except the strain at RR of the bonded specimen, the strains increased almost linearly as the displacement increased. The strain of the strand located at LR of the specimen reinforced with bonded strand is larger than that of the strand at RR, which is due to the larger cracks formed near LR than those formed near RR. However the variations of the strains observed in the specimen with unbonded strand are similar to each other, which implies that damages occurred nearly symmetrically in the two beams.

Figures 17 and 18 depict the variation of the rebar strain in the specimens strengthened with bonded and unbonded strand, respectively. It can be observed that at the vertical displacements around $350 \mathrm{~mm}$ the rebars which were initially under compression started to resist large tensile force due to catenary action.
Figure 19 shows the photographs of the damaged specimens reinforced with tendons. It was observed in the forcedisplacement relationship that the specimen with an unbonded strand showed catenary action superior to that of the specimen with bonded strand. This is due to the fact that in the specimen with a bonded strand the catenary force of the strand was transmitted to the beams evenly along the length, which resulted in separation of the beam from the column face as can be observed in the photograph of the specimen at failure shown in Fig. 19a. However in the specimen strengthened with unbonded strand, where all catenary force in the strand acts on the far face of the exterior column, the beam end was not separated from the column face even at the maximum displacement as can be observed in Fig. 19b. It was observed that, compared with the crack 


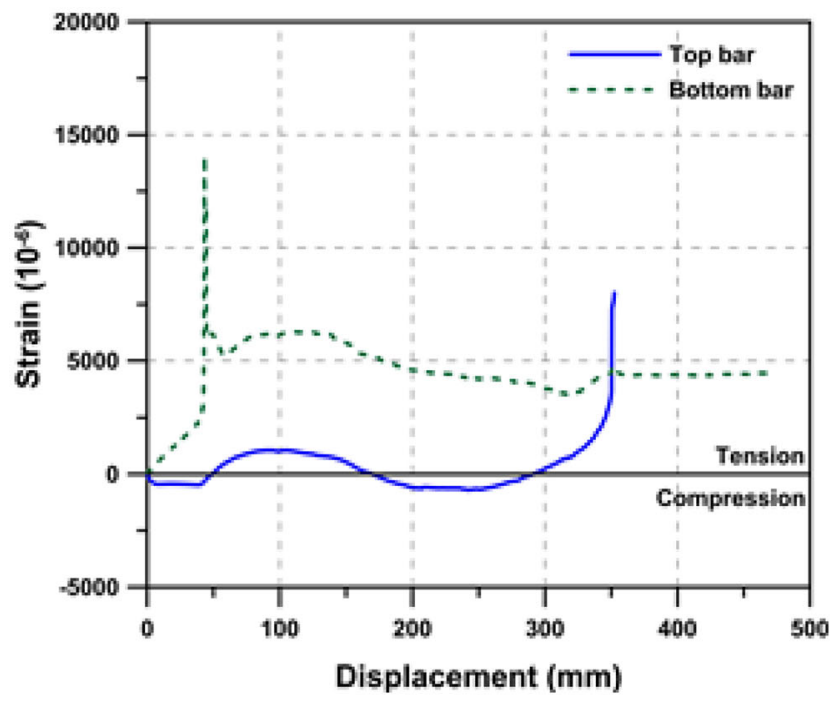

(a)

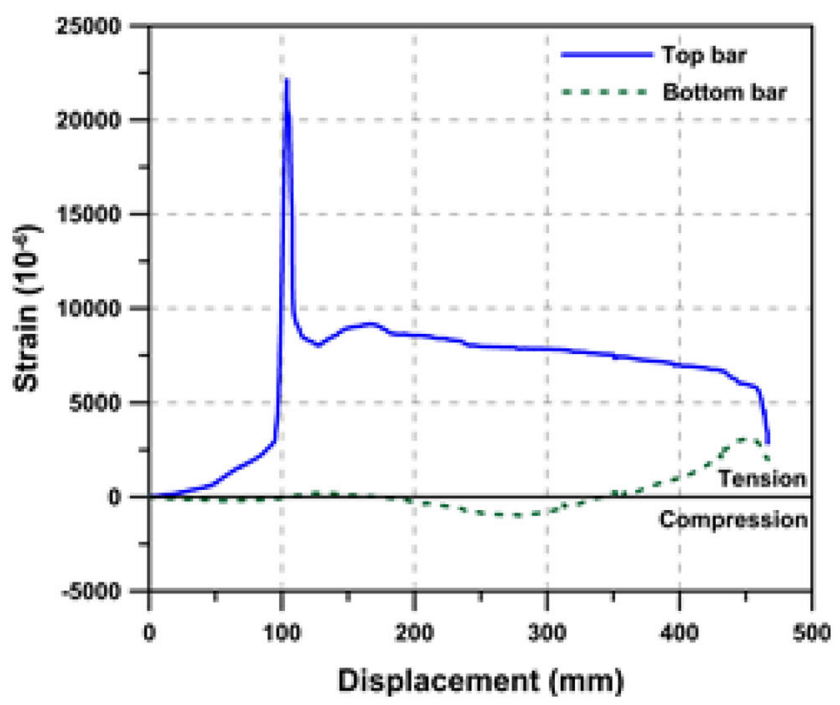

(b)

Fig. 18 Strain of rebars in the right-hand side beam of the gravity load resisting specimen strengthened by unbonded strand. a Left end $(\mathrm{RL})$. b Right end (RR).

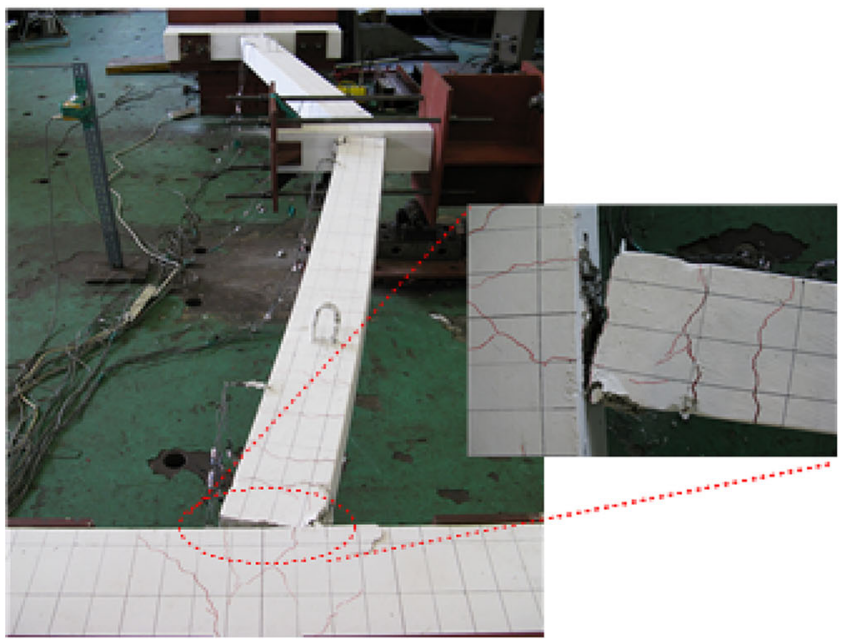

(a)

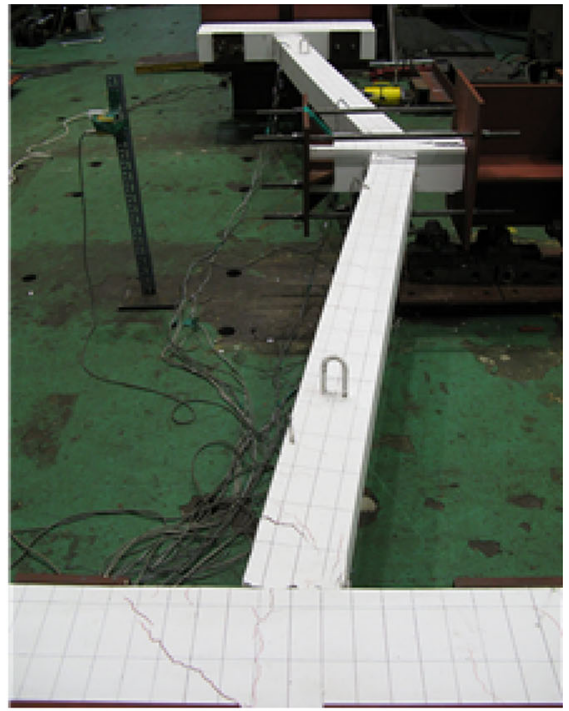

(b)

Fig. 19 Failure mode of the gravity-load resisting specimen strengthed by high strength strand. a Bonded strand. b Unbonded strand.

formation of the specimen without strand (shown in Fig. 9), smaller cracks formed relatively uniformly along the beam length reinforced with high strength strands. The number of cracks formed in the exterior beam-column joint of the specimen with unbonded strand turned out to be smaller than that in the specimen with bonded strand due mainly to the larger confinement effect of the unbonded strand and its anchorage. The cracks formed in the side columns of the specimens, however, may not be found in real buildings because the axial load imposed on the columns and the bending moment of the adjacent beam will compensate for the resultant tensile stress in the column joints.

Figure 20 shows the force-displacement relationship of the specimen reinforced with side plates at both sides of the beam-column joints. Plastic hinges formed at the displacement of about $90 \mathrm{~mm}$, and the specimen showed ductile behavior until the force increased again at the displacement of around $200 \mathrm{~mm}$ due to activation of catenary force. As no rebar was fractured until maximum displacement was reached, the force kept increasing without sudden drop as observed in the other specimens. Compared with the performance of the specimen strengthened with the high strength strands, the specimen reinforced with side plates showed slightly smaller strength but more stable behavior. Moreover, considering the higher expanse involved in the anchoring of strands, the side plate strengthening scheme seems to be more practical means of enhancing progressive collapse resisting capacity of RC moment frames.

The variation of re-bar strain in the specimen reinforced with side plates is shown in Fig. 21. It can be observed in Fig. 21a that the strain of the bottom bars of the left end of the right-hand-side beam, which was initially subjected to 


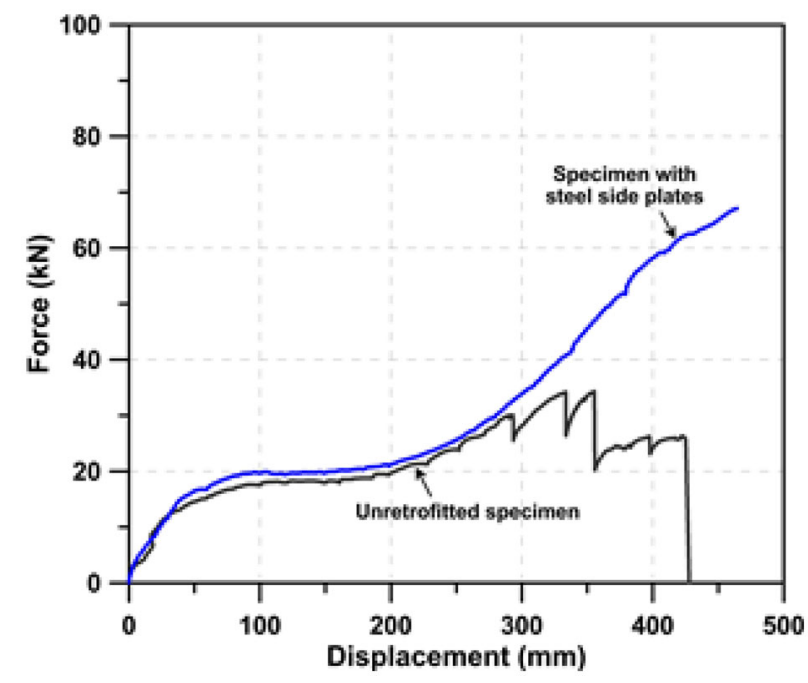

Fig. 20 Load-displacement relationship of the specimen reinforced with steel side plates. tension, increased until the displacement reached about $180 \mathrm{~mm}$ and decreased due to formation of cracks. However the strain of the top bars at the same location, which was initially under compression, started to resist tension after the displacement exceeded $247 \mathrm{~mm}$ due to the initiation of catenary action. Similar phenomenon was observed in the rebars located in the right end of the right-hand-side beam as shown in Fig. 21b. In this case the bottom bars were subjected to tension starting from the displacement of $290 \mathrm{~mm}$ due to catenary action.

Figure 22 shows the damaged ends of the specimen reinforced with side plates after the test is over. It can be seen that major cracks formed at the end of the side plates, which is $160 \mathrm{~mm}$ away from the column face. No major crack was observed within the region covered by the side plates, which is probably due to the confining effect of the plates with stud bolts. It was also observed that due to the catenary force many tension cracks formed along the beam length.

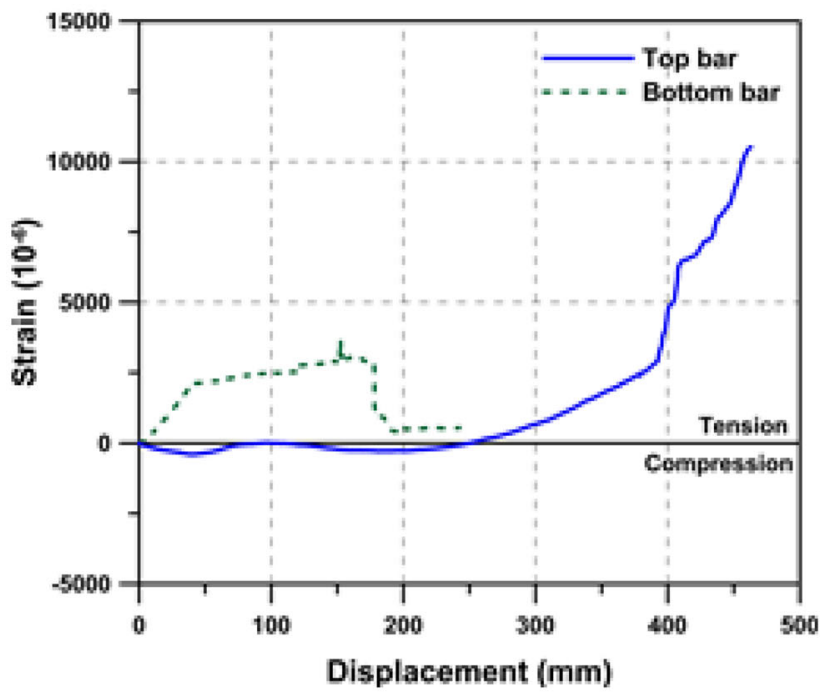

(a)

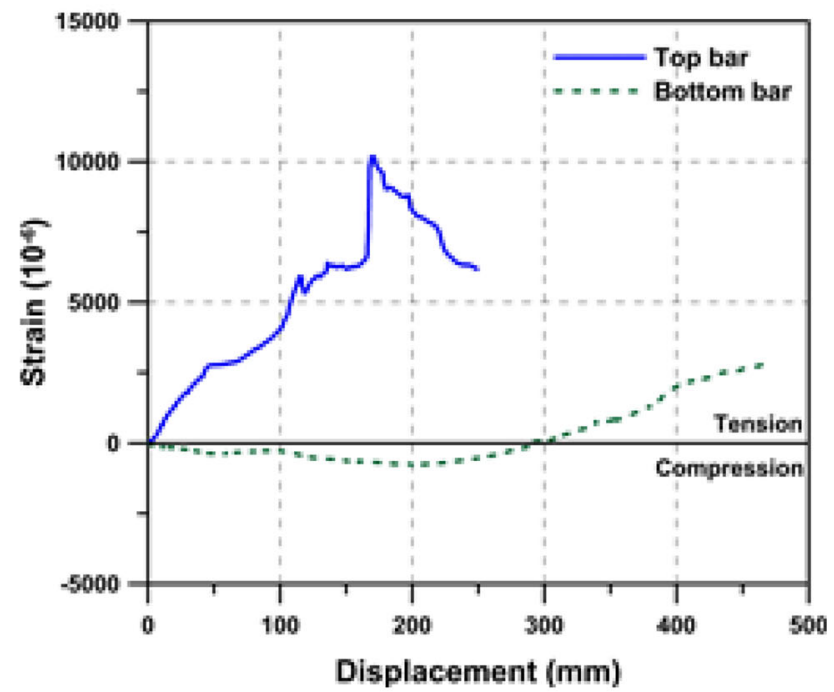

(b)

Fig. 21 Strain of rebars in the right-hand side beam of the specimen reinforced with side plates. a Left end (LL). b Right end (RR).

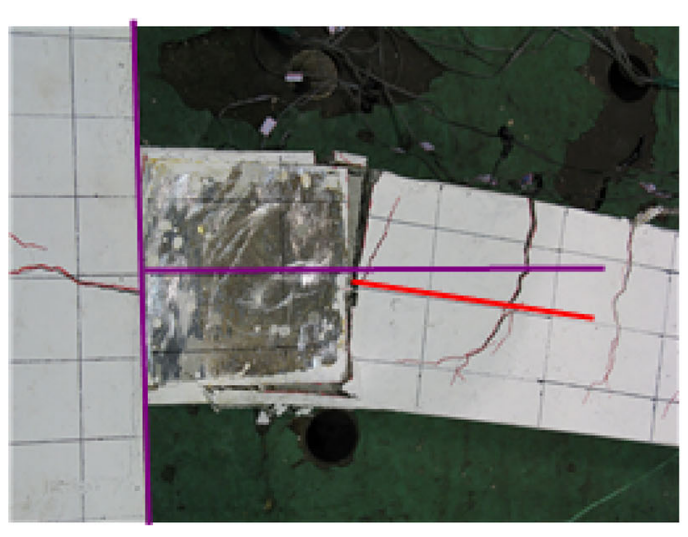

(a)

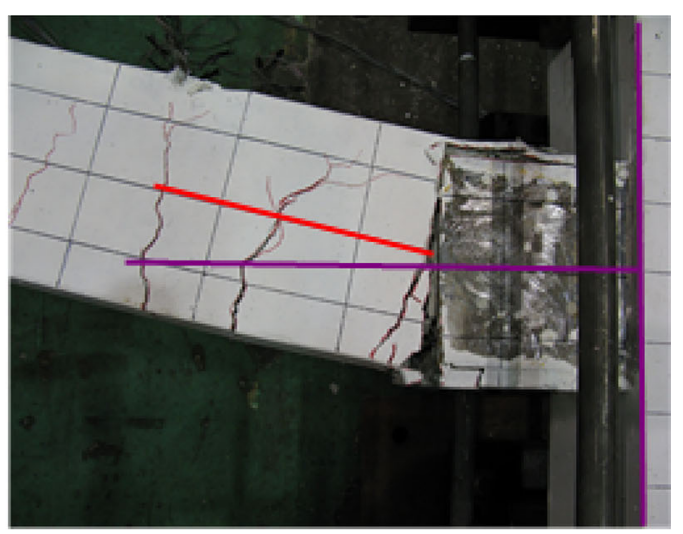

(b)

Fig. 22 Failure mode of the specimen strengthed by side plates. a Left end (LL). b Right end (RR). 


\section{Conclusion}

In this study the progressive collapse resisting capacity of RC beam-column subassemblages with and without strengthening was investigated by a series of displacement controlled static loading tests. The test results showed that the unstrengthened gravity load-resisting specimen failed by fractures of re-bars in the beams, and that due to the activation of the catenary action the maximum displacement at failure turned out to be significantly larger than the limit state for beams recommended in the GSA and DoD guidelines. In the other specimens no failure was observed until the maximum displacement capacity of the actuator was reached. The specimen designed for lateral load showed higher strength and deformation capacity than the specimen designed only for gravity load. Highest strength was observed in the structure with unbonded strand. The test result for the specimen with side steel plates in beam-column joints showed that the force-displacement curve increased without fracture of re-bars. Compared with the performance of the specimen strengthened with the high strength strands, the specimen reinforced with side plates showed slightly smaller strength but more stable behavior. Considering the higher expanse involved in the prestressing of members, the side plate strengthening scheme seems to be more practical means of enhancing progressive collapse resisting capacity of RC moment frames. Based on the test results it was concluded that the progressive collapse resisting capacity of a RC frame could be significantly enhanced using unbonded strands or steel side plates in the beam-column subassemblages exposed to abnormal loads.

Finally it should be pointed out that, as the tests were carried out using 2D beam-column subassemblages, the $3 \mathrm{D}$ effects of transverse frames and floor slabs could not be considered in this study, which can provide significant resistance against progressive collapse as pointed out by Qian et al. (2015). Also the dynamic effect caused by sudden removal of a column could not be considered in this study of static loading tests.

\section{Acknowledgments}

This research was supported by a grant (13AUDP-B06608301) from Architecture \& Urban Development Research Program funded by Ministry of Land, Infrastructure and Transport of Korean government.

\section{Open Access}

This article is distributed under the terms of the Creative Commons Attribution 4.0 International License (http:// creativecommons.org/licenses/by/4.0/), which permits unrestricted use, distribution, and reproduction in any medium, provided you give appropriate credit to the original author(s) and the source, provide a link to the Creative Commons license, and indicate if changes were made.

\section{References}

ACI Committee 315. (2004). ACI Detailing Manual-2004. Farmington Hills, MI: Publication SP-66(04), American Concrete Institute.

Choi, H., \& Kim, J. (2011). Progressive collapse-resisting capacity of reinforced concrete beam-column subassemblage. Magazine of Concrete Research, 63(4), 297-310.

Ellingwood, B. R., Smilowitz, R., Dusenberry, D. O., Duthinh, D., Lew, H. S., \& Carino, N. J. (2007). Best practices for reducing the potential for progressive collapse in buildings, Report No. NISTIR 7396, National Institute of Standards for Technology.

General Services Administration. (2003). Progressive collapse analysis and design guidelines for new federal office buildings and major modernization projects. Washington, DC: General Services Administration.

Harajli, M. H. (1993). Strengthening of concrete beams by external prestressing. PCI Journal, 38(6), 76-88.

ICC. (2009). International building code. Falls Church, VA: International Code Council.

Kang, S. B., Tan, K. H., \& Yang, E. H. (2015). Progressive collapse resistance of precast beam-column sub-assemblages with engineered cementitious composites. Engineering Structures, 98(1), 186-200.

Khandelwal, K., \& El-Tawil, S. (2005). Progressive collapse of moment resisting steel frame buildings, Proceedings of the 2005 Structures Congress and the 2005 Forensic Engineering Symposium, New York, NY.

Kim, J., \& An, D. (2009). Evaluation of progressive collapse potential of steel moment frames considering catenary action. The Structural Design of Tall and Special Buildings, 18(4), 455-465.

Milner, D., Gran, J., Lawver, D., Vaughan, D., Vanadit-Ellis, W., \& Levine, H. (2007). FLEX analysis and scaled testing for prediction of progressive collapse, first international workshop on performance, protection \& strengthening of structures under extreme loading (PROTECT 2007). Canada: Whistler.

Powell, G. (2005). Progressive collapse: Case studies using nonlinear analysis: Proceedings of the 2005 Structures Congress and the 2005 Forensic Engineering Symposium, New York, NY.

Qian, K., \& Li, B. (2012). Dynamic performance of RC beamcolumn substructures under the scenario of the loss of a corner column - experimental results. Engineering Structures, 42, 154-167.

Qian, K., \& Li, B. (2013). Performance of three-dimensional reinforced concrete beam-column substructures under loss of a corner column scenario. ASCE Journal of Structural Engineering, 139(4), 584-594.

Qian, K., Li, B., \& Ma, J. X. (2015). Load carrying mechanism to resist progressive collapse of RC buildings. ASCE Journal of Structural Engineering, 141(2), 04014107.

Ren, W., Sneed, L. H., Gai, Y., \& Kang, X. (2015). Test results and nonlinear analysis of RC T-beams strengthened by bonded steel plates. International Journal of Concrete Structures and Materials, 9(2), 133-143. 
Sasani, M., \& Kropelnicki, J. (2008). Progressive collapse analysis of an RC structure. The Structural Design of Tall and Special Buildings, 17(4), 757-771.

Shin, K.-J., Lee, S.-H., \& Kang, T. H.-K. (2013). External posttensioning of reinforced concrete beams using a V-shaped steel rod system. ASCE Journal of Structural Engineering, 140(3), 04013067.

Song, B. I., \& Sezen, H. (2013). Experimental and analytical progressive collapse assessment of a steel frame building. Engineering Structures, 56, 664-672.

Tsai, M. H., \& Lin, B. H. (2008). Investigation of progressive collapse resistance and inelastic response for an earthquake-resistant RC building subjected to column failure. Engineering Structures, 30(12), 3619-3628.

Yi, W. J., He, Q. F., Xiao, Y., \& Kunnath, S. K. (2008). Experimental study on progressive collapse-resistant behavior of reinforced concrete frame structures. $A C I$ Structural Journal, 105(4), 433-439.

Yu, J., \& Tan, K. H. (2013). Experimental and numerical investigation on progressive collapse resistance of reinforced concrete beam column sub-assemblages. Engineering Structures, 55, 90-106. 